\title{
Profiles of lead in urban dust and the effect of the distance to multi-industry in an old heavy industry city in China
}

\author{
Yang $\mathrm{Yu}^{1,2}$, Yingxia $\mathrm{Li}^{1}{ }^{*}, \mathrm{Ben}_{\mathrm{Li}^{2}}$, Zhenyao Shen ${ }^{1}$, Michael K. Stenstrom ${ }^{2}$
}

\begin{abstract}
:
Lead $(\mathrm{Pb})$ concentration in urban dust is often higher than background concentrations and can result in a wide range of health risks to local communities. To understand $\mathrm{Pb}$ distribution in urban dust and how multi-industrial activity affects $\mathrm{Pb}$ concentration, 21 sampling sites within the heavy industry city of Jilin, China, were analyzed for $\mathrm{Pb}$ concentration. $\mathrm{Pb}$ concentrations of all 21 urban dust samples from the Jilin City Center were higher than the background concentration for soil in Jilin Province. The analyses show that distance to industry is an important parameter determining health risks associated with $\mathrm{Pb}$ in urban dust. The $\mathrm{Pb}$ concentration showed an exponential decrease, with increasing distance from industry. Both maximum likelihood estimation and Bayesian analysis were used to estimate the exponential relationship between $\mathrm{Pb}$ concentration and distance to multi-industry areas. We found that Bayesian analysis was a better method with less uncertainty for estimating $\mathrm{Pb}$ dust concentrations based on their distance to multi-industry, and this approach is recommended for further study.
\end{abstract}

Keywords: Bayesian analysis, health risk assessment, lead, maximum likelihood estimation, Monte Carlo simulation, urban nonpoint source pollution 


\section{Introduction}

In recent years, rapid industrialization and urbanization have been achieved with a large environmental sacrifice, especially in developing countries, such as China (Li et al., 2016). As one of the largest global producers and consumers, China is facing heavy metal pollution, linked to antimony $(\mathrm{Sb})$, iron $(\mathrm{Fe})$, lead $(\mathrm{Pb})$ and zinc $(\mathrm{Zn})$ among others (Gunson and Jian, 2001, Li et al., 2014). Metals emitted from various urban activities and industrial processes tend to accumulate in various media, especially in dust, soil, atmospheric particles, and urban runoff; they are difficult to remove from these media, even after many years (Lau and Stenstrom, 2005; Madarang and Kang, 2014; Liu et al., 2015; Maniquiz-Redillas and Kim, 2016). Urban dust is considered a good indicator of metal contamination from human and industrial activities in urban environments (Žibret, 2013; Žibret et al., 2013; Zhao and Li, 2013; Acosta et al., 2015; Song et al., 2015; Yu et al., 2016). High metal concentrations have often been found in urban dust, and numerous studies have focused on this metal pollution (Apeagyei et al., 2011; Li et al., 2013a; Huang et al., 2014). Urban dust also is an important source for human exposure to metals through inhalation, direct ingestion, and dermal contact (Zheng et al., 2010; Shi et al., 2011).

Metal exposure has a cumulative effect and can result in a wide range of health problems; it is especially problematic for children (De Miguel et al., 2007; Guney et al., 2010). For example, $\mathrm{Pb}$, known as the "chemical time bomb" (Stigliani et al., 1991) and as a neurotoxin, is harmful to neurodevelopment, brain development, and kidney development in children, even at low concentrations (Kim et al., 2013). Therefore, there is an increasing need for information regarding $\mathrm{Pb}$ pollution status in urban dust to mitigate and control $\mathrm{Pb}$ health risks. 
The United States Environmental Protection Agency's (USEPA) health risk assessment model was often used to estimate the potential risks related to exposure to $\mathrm{Pb}$ from urban dust (USEPA, 2011).

Normally, the sources of $\mathrm{Pb}$ in urban dust include industrial activities (Žibret and Šajn, 2008; Ordóñez et al., 2015; Qing et al., 2015), traffic-related activities (Lu et al., 2009; Yu et al., 2016), coal combustion (Cheng and $\mathrm{Hu}, 2010)$, atmospheric deposition ( $\mathrm{Li}$ et al., 2016) and smaller, site-specific sources. Higher rates of $\mathrm{Pb}$ pollution have often been found around industrial areas, related to specific industries or activities (Al-Khashman, 2004; Chen et al., 2009).

Many studies have focused on the relationship between a single industry and its $\mathrm{Pb}$ pollution (Žibret and Šajn, 2008; Li et al., 2013c). Typically, the Pb in urban dust exponentially decreases with increasing distance from a given industry (Wang et al., 2003; Wang et al., 2006; Wu et al., 2011; Ordóñez et al., 2015). Therefore, the Pb pollution status at an unsampled site can be estimated using an exponential equation, based on the distance from this single industry. However, for many countries, such as China (Yang et al., 2010), Italy (Imperato et al., 2003), and Spain (Acosta et al., 2014), there are many industries located together, and identifying a specific source is difficult. Clearly, more research is needed to understand and estimate the combined influence of many industries on $\mathrm{Pb}$ concentration distributions. In this study, we used maximum likelihood estimation (MLE) and Bayesian analysis (BA) to develop a model for the relationship between multiple industrial sites and $\mathrm{Pb}$ pollution.

The objectives of this study were (1) to analyze the $\mathrm{Pb}$ spatial distributions in urban dust of Jilin City Center (JLC); (2) to assess the health risks of exposure to $\mathrm{Pb}$ in urban dust; (3) to show 
the influence on urban dust $\mathrm{Pb}$ concentrations from specific industries using MLE and BA methods, and (4) to determine the uncertainty of estimates based on MLE and BA methods. Results of this study will contribute to understanding the influence of multiple industrial sources on $\mathrm{Pb}$ distribution in urban dust and help identify measures that can reduce $\mathrm{Pb}$ exposure in local populations.

\section{Materials and methods}

\subsection{Sample collection and pretreatment}

Jilin City is the second largest city in Jilin Province, northeastern China, with a total area of $27,120 \mathrm{~km}^{2}$ and a population of nearly 4.3 million (JLESSY, 2013). It plays an important part in the growing chemical industry of China. Since 2001, Jilin City's total industrial output has increased markedly, and continues to grow, having a 2013 output $9.7 \%$ higher than in 2012 (JLESSY, 2013). As a growing industrial city, there are many associated environmental challenges. This is compounded by the fact that there are many industries located in Jilin City Center (JLC) and also many people lived in JLC.

Fig. 1 presents a map of JLC showing the location of sampling sites and major heavy industries. A total of 21 urban dust samples were collected from 21 evenly distributed sites on October 19, 2012. At each sampling sites (1 to 21), the height of the column shown in Fig. 1 is proportional to the measured $\mathrm{Pb}$ concentration. Detailed information about these sampling sites is given in Supplementary Table ST1. Specifically industrial sites are numbered i1 to i8 in Fig. 1. Given the large number of heavy industrial companies in Jilin City (with a listing of 1448 Industrial Enterprises above Designated Size in 2012) (JLESSY, 2013), only the top 20 prime 
operating revenue companies within the study area, along with the sampling sites (10 and 12) from industries are shown in Fig. 1. More information on these industries can be found in Supplementary Table ST2.

Fig. 1 Sampling site and major industry locations in Jilin City Center (JLC), China

As described in our previous study (Li et al., 2016), urban dust samples were carefully collected within $0.5 \mathrm{~m}$ of the road curb or edge at each site, using a $15 \mathrm{~cm}$ brush and a plastic dustpan. Sweeping was repeated back and forth at least three times to collect surface particles. At least $300 \mathrm{~g}$ of particles were collected at each site. Sampling was carried out at least 7 days after rainfall. The collected samples were stored in self-sealing plastic bags and immediately transported to the laboratory. The samples were air-dried for 15 days in the laboratory and then sieved through a $500 \mu \mathrm{m}$ opening nylon sieve to remove large particles, including stones, leaves, small pieces of bricks, cigarette butts, and other litter. The sieved dust samples were ground to powder, having a grain size less than $200 \mu \mathrm{m}$ in diameter, to facilitate digestion, and stored at $4^{\circ} \mathrm{C}$ prior to analysis.

\subsection{Metal measurement, quality control and quality assurance}

Approximately $0.5 \mathrm{~g}$ of the ground sample powder was digested using hydrofluoric acid, nitric acid, perchloric acid, and aqua regia according to the National Standard method for China (GB15618, 1995). Pb concentrations were measured using inductively coupled plasma-mass spectrometry (ICP-MS, American Thermo Electron Corporation X series II).

The detection limit of $\mathrm{Pb}$ was $2 \mu \mathrm{g} / \mathrm{g}$. Three samples out of the overall 21 samples were selected to run as duplicate sample analyses for quality assurance. The recovery rate was 
determined by adding geochemical reference materials (e.g., GSS17, GSS25, GSS26) (three samples). The average recovery rate was calculated to be $100.6 \%$.

\subsection{Data analysis}

Descriptive statistical analyses were performed using Microsoft Excel 2010 (Microsoft Corp., Albuquerque, NM, USA) and the freely available "R" statistical software package (R Core Team), version 3.2.4. The MLE and BA routines in $\mathrm{R}$ were used to test the influence of various industries on $\mathrm{Pb}$ concentration in urban dust. Both routines search for a set of parameters to maximize probability. ArcGIS 10.0 (Esri, Redlands, CA, USA) was used for spatial calculations and to create Fig. 1. The health risk at each sampling site was estimated for ingestion, inhalation and dermal contact using USEPA methods described in the section 2.3.1 belows. The health risk at locations other than sampling sites was estimated using ArcGIS 10.0's inverse distance weighting (IDW) function as shown in Fig. 2. Origin 8 (OriginLab Corp., Northampton, MA, USA) was used to estimate the lead concentration, as shown in Fig. 3. The data for Fig. 4 were estimated using R, while the figure was drawn using SPSS 19.0 (IBM Corp., Armonk, NY, USA). These estimation methods are described in more detail in the following sections.

\subsubsection{Health risk assessment model}

\subsubsection{Exposure dose}

In this study, the health risk assessment model developed by the USEPA (USEPA, 2011) was used to estimate the exposure of children and adults to $\mathrm{Pb}$ in urban dust. The model was applied in this study with the following assumptions: (1) humans are exposed to urban dust metals through three main pathways (direct ingestion, inhalation through the mouth and nose, and dermal contact 
with urban dust particles that adhere to exposed skin); (2) intake rates and particle emissions can be approximated using soil intake rates and particle emission parameterizations; (3) some human exposure parameters in the observed area are similar to parameters of the reference study area; (4) the total non-carcinogenic risk can be estimated for $\mathrm{Pb}$ by summing the individual risks obtained for the three exposure pathways.

Estimates of the average daily doses of $\mathrm{Pb}$ through the three exposure pathways were estimated using the following equations:

$$
\begin{aligned}
& A D D_{\text {ing }}=\frac{c \times I n g R \times E F \times E D}{B W \times A T} \times C F \\
& A D D_{\text {inh }}=\frac{c \times I n h R \times E F \times E D}{P E F \times B W \times A T} \\
& A D D_{\text {derm }}=\frac{c \times S A \times S L \times A B S \times E F \times E D}{B W \times A T} \times C F
\end{aligned}
$$

where $A D D_{\text {ing }}, A D D_{\text {inh }}$ and $A D D_{\text {derm }}$ are the average daily doses of $\mathrm{Pb}$ through ingestion, inhalation and dermal contact, respectively; $c$ is the $\mathrm{Pb}$ concentration in urban dust $(\mu \mathrm{g} / \mathrm{g}) ; \operatorname{Ing} R$ and $I n h R$ are the ingestion and inhalation rates; $E F$ is the exposure frequency; $E D$ is the exposure duration; $B W$ is body weight; $A T$ is the average time of exposure for non-carcinogens; $P E F$ is the particle emission factor; $S A$ is the exposed skin area; $S L$ is the skin adherence factor; and $A B S$ is the dermal absorption factor. $C F$ is equal to $10^{-6}$, and is a conversion factor used to unify the different units used in equation (1) and (3). The units and parameters values used in equations (13) are shown in Table 1.

Model parameters have been developed from specific pollutant concentrations, local social conditions, and USEPA-recommended parameter values for which local values are not available (Chabukdhara and Nema, 2013; Li et al., 2013b; Yekeen et al., 2016). The parameter estimates 
from local or similar environments were used preferentially to improve the reliability of our

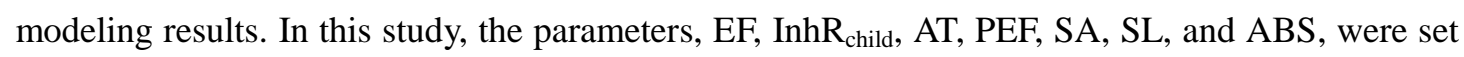
according to values of Beijing, given by the Beijing Municipal Research Institute of Environmental Protection (BMRIEP, 2007; 2009), as shown in Table 1. The parameters for Jilin City were likely similar to those for Beijing. The Ministry of Environmental Protection of the People's Republic of China (MEPC, 2013) sets values for China for adult BW of $60.6 \mathrm{~kg}$, and the $\operatorname{InhR}_{\text {adult }}$ of 15.7. Given the easy transformation between surface soil and urban dust, the USEPA values of IngR for combined soil and dust (USEPA, 2011) were used in this study. Values for ED and $\mathrm{BW}_{\text {child }}$ were set according to the USEPA suggestions (USEPA, 2011).

Table 1 Exposure factor definitions and values for the urban dust daily dose model

\subsubsection{Risk characterization}

For human exposure to $\mathrm{Pb}$ in urban dust, there are only non-carcinogenic risks, which can be evaluated using $\mathrm{ADD}_{\text {ing }}, \mathrm{ADD}_{\text {inh }}$, and $\mathrm{ADD}_{\text {derm }}$ with in the following equations:

$$
\begin{aligned}
& H Q_{p}=\frac{A D D_{p}}{R f D_{p}} ; \text { where } p=\text { ing, inh, derm } \\
& H I=\sum_{p} H Q_{p}
\end{aligned}
$$

where, the hazard quotient $\left(H Q_{p}\right)$ represents the non-carcinogenic risk of $\mathrm{Pb}$ through exposure pathway $p$, corresponding to one of the three exposure pathways-i.e., direct ingestion (ing), inhalation through the mouth and nose (inh), and dermal contact with urban dust particles (derm). The reference doses $(\mathrm{RfD}, \mathrm{mg} /(\mathrm{kg} \bullet \mathrm{d}))$ is an estimation of the maximum permissible risk to the human population through daily exposure during a lifetime. Considering the $\mathrm{RfD}$ value of $\mathrm{Pb}$ for a child, the chronic dietary exposure corresponding to a decrease of 1 IQ point was estimated 
to be $0.012 \mathrm{mg} /$ day (WHO, 2011). Given that average child body weight used in our study is 42.7 $\mathrm{kg}$, then the ingestion RfD for child was calculated to be $0.28 \mathrm{mg} /(\mathrm{kg} \bullet \mathrm{d})$ (i.e., $0.012 \mathrm{mg} / \mathrm{day} \div 42.7$ $\mathrm{kg})$. A value of $0.0013 \mathrm{mg} /(\mathrm{kg} \bullet \mathrm{d})$ for adult ingestion RfD was used here, as suggested in WHO (2011). According to the US Department of Energy's RAIS (US Department of Energy, 2004), the RfDs for $\mathrm{Pb}$ used there were 0.00352 for inhalation, and 0.000525 for dermal contact. The hazard index $(H I)$ represents the non-carcinogenic health risk for $\mathrm{Pb}$ as the sum of the three exposure pathways. If $H I$ (non-cancer risk) is $<1$, then it is assumed that there is no significant non-carcinogenic risk; however, if $H I$ is $>1$, then there is a chance that non-carcinogenic effects may occur (Ferreira-Baptista and De Miguel, 2005).

\subsubsection{Inverse distance weighting}

IDW is an interpolation method widely applied to assess spatial distributions linked to many parameters. IDW assumes that predictions are a linear combination of all available data, weighted according to their distance from the interpolation point. In this study, IDW interpolation with a power of 2, and neighboring sample number of 12 was applied to visualize the spatial distribution of $\mathrm{HI}$ in urban dust using ArcGIS 10.0.

\subsubsection{Maximum likelihood estimation and Bayesian Analysis}

MLE is one of the most widely used methods for estimating the unknown parameters of a model. A set of values for the model parameters was selected to maximize the likelihood function. Intuitively, this maximizes the "agreement" between the model and the observed data. A confidence interval, containing a parameter value with a specific probability was obtained by repeating this process using different values. Confidence intervals are commonly based on 
asymptotic theory and a normal error structure, and they typically have a symmetric distribution. In this study, MLE was used to estimate the relationship between $\mathrm{Pb}$ concentration and distance from various industries.

Bayesian posteriors define the probability distribution (nonparametrically) for a parameter value, and direct probabilistic statements can be made from that distribution. Bayesian methods address both uncertainty and parameter estimation in the modeling process. The initial values of BA were set according to the results of MLE. The parameters (coefficients) of the model were considered to be random variables, and 10,000 values of posterior coefficients were estimated using a Monte Carlo simulation. These were used to assess uncertainty in the prediction model.

\section{Results and discussion}

\subsection{Characteristics of lead in urban dust}

The $\mathrm{Pb}$ concentration in JLC urban dust ranged from $36.42 \mu \mathrm{g} / \mathrm{g}$ (JLC6) to $339.51 \mu \mathrm{g} / \mathrm{g}$ (JLC17), with a mean value of $75.60 \mu \mathrm{g} / \mathrm{g}$, as shown in Fig. 1. The $\mathrm{Pb}$ concentrations in all samples were higher than the soil background concentration for Jilin Province ( $28.8 \mu \mathrm{g} / \mathrm{g}$; CNEMC, 1990). The standard deviation (SD) was 62.73, similar in magnitude to the mean value, showing a large variation between samples.

Fig. 1 shows concentrations (green histogram) at various samples and industrial sites (black triangle, $\mathbf{\Delta})$. Higher $\mathrm{Pb}$ concentrations close to the industrial areas suggests that industrial sources have more influence on $\mathrm{Pb}$ level in urban dust than other sources. The samples around industrial sites, except for the highest $\mathrm{Pb}$ concentration at site $\mathrm{JLC} 17$, all had similar $\mathrm{Pb}$ pollution levels in urban dust, especially for samples from industrial sites in north JLC. The high concentrations and 
the proximity of our sampling sites to industrial sites are not obvious in Fig. 1, but become more apparent in our MLE and BA, as discussed later.

Table 2 shows seven industries in north JLC and their main $\mathrm{Pb}$ emission. The primary $\mathrm{Pb}$-producing activities of these seven industries are coal burning and petroleum chemical refining. The emission rates from coal and petroleum are low compared with other sources (such as the ferroalloy industry, as discussed in section 3.3) and were assumed to have the same value in our modeling. Three other industries in north JLC (i.e., i1, i2, i2b) are office buildings, without any $\mathrm{Pb}$ emission sources; they are not shown in Table 2.

The highest $\mathrm{Pb}$ concentration was measured at JLC17 (339.51 $\mu \mathrm{g} / \mathrm{g})$, adjacent to Sinosteel Jilin Ferroalloy Co., Ltd. The Pb concentration at JLC17 was more than three times higher than at the next highest sampling site, JLC12, with a level of $108.41 \mu \mathrm{g} / \mathrm{g}$. At the Sinosteel Jilin Ferroalloy Co., Ltd., the main $\mathrm{Pb}$ emission are coal burning and iron ore smelting; therefore, it had a more obvious influence on $\mathrm{Pb}$ pollution in urban dust around it than other industries. Compared with $\mathrm{Pb}$ concentrations in other industrial cities, the $\mathrm{Pb}$ concentration at JLC17 was of a moderate level. It was clearly higher than sites in some other industrial cities, such as Tongchuan urban area (maximum $\mathrm{Pb}$ concentration of $134.7 \mu \mathrm{g} / \mathrm{g}$ ) ( $\mathrm{Lu}$ et al., 2014), and Yaozhou district (maximum $\mathrm{Pb}$ concentration of $125.9 \mu \mathrm{g} / \mathrm{g}$ ) (Lu et al., 2014) in China, as well as Karak Industrial Estate in Jordan (steel and non-steel industry, maximum $\mathrm{Pb}$ concentration of $22.3 \mu \mathrm{g} / \mathrm{g}$ ) (Al-Khashman, 2004). However, it was lower than levels in an industrial town in NW Spain (maximum $\mathrm{Pb}$ concentration of $1482 \mu \mathrm{g} / \mathrm{g}$ ) (Ordóñez et al., 2015). 
Table 2 Main sources of $\mathrm{Pb}$ emission from various industries in the north of Jilin City Center

\subsection{Health risk assessment of exposure to $\mathrm{Pb}$ in urban dust}

The non-carcinogenic risk of exposure to $\mathrm{Pb}$ in urban dust through the three exposure pathways was estimated using equation (4). The HI, representing the sum of the risks from all three pathways, was also determined. The results of non-carcinogenic risk of exposure to $\mathrm{Pb}$ through each exposure pathway is shown in Supplementary Table ST3. For both children and adults, direct ingestion was the main exposure pathway. The $\mathrm{HI}$ value of $\mathrm{Pb}$ for children was nearly an order of magnitude higher than for adults, confirming that children face a greater exposure risk to $\mathrm{Pb}$ in urban dust. Almost half of the $\mathrm{HI}$ values for children for our samples were higher than 1, indicating a high exposure risk. In contrast, $\mathrm{HI}$ values for adults were all lower than 1, showing no significant exposure risks for adults in the study area. A concern for the health risks related to $\mathrm{Pb}$ is still important, although most $\mathrm{HI}$ values were low, because in managing overall $\mathrm{Pb}$ risk, all sources must be considered, including those from the soil and atmosphere, as well as other sources not considered in this study, e.g. drinking water and food. There is a significant degree of uncertainty linked to the lack of reports and investigations on $\mathrm{Pb}$ exposure parameters in China. In addition, our assessment of the $\mathrm{Pb}$ health risks related to exposure to urban dust was affected by the limited number of our observations in the study area.

The spatial distribution of $\mathrm{HI}$ values for $\mathrm{Pb}$ in urban dust, as shown in Fig. 2, indicates that there were more $\mathrm{Pb}$ exposure risks for children than adults. Greater dermal contact and ingestion rates for children caused higher HI values. Given that, the difference between children and adults needed to be assessed and that there were huge differences between them, we needed to use many 
HI classes, as shown in Fig.2. The HI values for adults were less than 1.0 for all areas of JLC, while the $\mathrm{HI}$ values for children ranged from 0.56 to 5.12 . The lower risk area occurs in the central part of JLC, where there are fewest industrial sources, as indicated by the density of black triangles $(\boldsymbol{\Delta})$. This central part of JLC also had lower HI values than other parts of the city, especially compared with the northern area of JLC, located nearer to industries. This distribution suggests that industries had a great influence on $\mathrm{Pb}$ health risks to local population. The most obvious $\mathrm{Pb}$ risk source is from the ferroalloy industry, near sampling site JLC17. However, other industries, aside from JLC17, had similar levels of health risk related to $\mathrm{Pb}$ in urban dust.

Fig. 2 Spatial distribution of health risk assessment through exposure to $\mathrm{Pb}$ in urban dust

\subsection{Influence of distance from industries}

\subsubsection{Model development between $\mathrm{Pb}$ concentration and distance}

\section{from industries}

As mentioned above, higher $\mathrm{Pb}$ concentrations and health risks occurred in the areas around industries. To understand the influence of industry on the $\mathrm{Pb}$ distribution, we modeled $\mathrm{Pb}$ concentrations as a function of distance from various industries. Previous research (Žibret and Šajn, 2008; Zheng et al., 2010; Ordóñez et al., 2015) has shown that metal concentrations in urban dust related to industry, decrease with increasing distance from the industrial site. Typically, metal concentrations exponentially decrease within a short distance from their source (Wang et al., 2003; Wu et al., 2011). Many industries located within the study area, with the single exception of JLC17, had a similar influence on $\mathrm{Pb}$ concentrations in urban dust, and their associated health risks. However, it was difficult to distinguish pollution from any specific industrial site. The 
industries in the northern part of JLC (i1a, i1b, i1c, i1d, i1e, i2a, JLC10; Table 2) were selected as a case study, using samples that were collected from the northern part of JLC, which were $3 \mathrm{~km}$ from at least one of these industries, i.e. samples JLC9, JLC10, JLC11, JLC12, JLC13, JLC14, and JLC15.

In the study area (north of Songhuajiang River), an exponential equation was chosen to model the relationship between $\mathrm{Pb}$ concentration and distance from multi-industry. Because the sampling sites are influenced by more than one industrial site, a generalized model was used to estimate the industrial influences, expressed as a weighted sum of the distances from all industries in the study area. Each industry was assumed to have the same properties; thus, source differences among industries were ignored. Equation 6 shows the exponential model used for all industries north of the river.

$$
C_{j}=\sum_{i=1}^{7} \beta_{0} e^{\beta_{1} D_{i, j}}
$$

where $C_{j}$ represents the predicted $\mathrm{Pb}$ concentration at a sampling site $\mathrm{j}$; $\mathrm{j}$ represents the seven sampling sites: JLC9, JLC10, JLC11, JLC12, JLC13, JLC14, and JLC15; $D_{i, j}$ represents the distance between sampling site $j$ and industry $i$; and $i$ represents the seven main industries in northern JLC, including i1a, i1b, i1c, i1d, i1e, i2a, and JLC10 (sampling site JLC10 was located at Guodian Jilin Thermoelectric Power Plant). Specific information on these industries is listed shown in Table 2. $\beta_{0}$ and $\beta_{1}$ are empirical coefficients estimated using MLE and BA.

A random error $\varepsilon$ was introduced into equation (6) when MLE and BA were used to estimate $\beta_{0}$ and $\beta_{1}$, as shown in equation (7) below:

$$
C_{j}^{0}=\sum_{i=1}^{7} \beta_{0} e^{\beta_{1} D_{i, j}}+\varepsilon_{j}
$$


where $C_{j}^{0}$ is the observed $\mathrm{Pb}$ concentration in the seven urban dust samples; and $\left\{\varepsilon_{\mathrm{j}}\right\}$ is an independently and identically distributed normal process with zero mean and variance $\sigma^{2}\left(\varepsilon_{j} \mid \sigma^{2} \sim\right.$ i.i.d. $\mathrm{N}\left(0, \sigma^{2}\right)$ ), which accounts for the uncertainty caused by factors other than distance.

For the MLE, the likelihood function was used, as follows:

$$
f(\text { Likelihood })=\exp \left(\sum_{j=1}^{n}\left(-\frac{1}{2} \times \log \left(2 \times \pi \times \sigma^{2}\right)-\frac{\left(c_{j}^{0}-C_{j}\right)^{2}}{2 \times \sigma^{2}}\right)\right)
$$

where $f$ (Likelihood) is the maximum likelihood function, which searches for values of $C_{j}^{0}$ and $C_{j}$ that maximize the likelihood, and $\mathrm{n}$ is the sample number.

The BA used Bayes' theorem as follows (Gelman et al., 2014):

$$
P(\beta \mid C)=\frac{P(C \mid \beta) P(\beta)}{P(C)} \propto P(C \mid \beta) P(\beta)
$$

where $\mathrm{P}(\beta \mid \mathrm{C})$ is the posterior probability of $\beta$, which is the conditional distribution of the parameters given the observed data; $\mathrm{P}(\beta)$ is the prior probability of $\beta$; and $\mathrm{P}(\mathrm{C} \mid \beta)$ is the likelihood function. For this study, the parameters were assumed to be independent and normally distributed $\left(\beta_{1} \sim \mathrm{N}\left(\mu_{1}, \sigma_{1}^{2}\right), \beta_{2} \sim \mathrm{N}\left(\mu_{2}, \sigma_{2}^{2}\right), \sigma^{2} \sim \mathrm{N}\left(\mu_{3}, \sigma_{3}^{2}\right)\right)$. The results obtained from the MLE were used as the initial values for $\mu_{1}, \sigma_{1}{ }^{2}, \mu_{2}, \sigma_{2}{ }^{2}, \mu_{3}, \sigma_{3}^{2}$, such that it rapidly obtained an appropriate value.

$$
\begin{aligned}
& f(\text { Bayes })= \\
& \quad\left(\prod_{j=1}^{n} \exp \left(-\frac{1}{2} \times \log \left(2 \times \pi \times \sigma^{2}\right)-\frac{\left(C_{j}^{0}-C_{j}\right)^{2}}{2 \times \sigma^{2}}\right)\right) \times \frac{1}{(2 \pi)^{\frac{3}{2}} \times \sigma_{1} \times \sigma_{2} \times \sigma_{3}} \times \exp \left(-\frac{\left(\beta_{1}-\mu_{1}\right)^{2}}{2 \sigma_{1}{ }^{2}}-\right. \\
& \quad \frac{\left(\beta_{2}-\mu_{2}\right)^{2}}{2 \sigma_{2}{ }^{2}}-\frac{\left(\sigma^{2}{ }_{-} \mu_{3}\right)^{2}}{2 \sigma_{3}{ }^{2}}
\end{aligned}
$$

where $f$ (Bayes) is the Bayesian routine; $\mathrm{n}$ is the sample number; and $\sigma_{1}{ }^{2}, \sigma_{2}{ }^{2}$, and $\sigma_{3}{ }^{2}$ are the variance for $\beta_{1}, \beta_{2}$, and $\sigma^{2}$, respectively. The prior distribution was obtained from equation (10).

A Monte Carlo simulation is widely used in Bayesian methods to create a large test dataset 
(Liu et al., 2008; Haddad et al., 2013; Egodawatta et al., 2014). The Markov Chain Monte Carlo method, a popular Monte Carlo simulation, was used in this study to obtain the posterior probability distributions. A total of 10,000 values were generated in each sample, yielding 10,000 set values for $\beta_{1}$ and $\beta_{2}$. These data converged quickly, because the MLE results were used as the initial values for the BA; while all 10,000 datasets were used to determine the uncertainty of the model.

\subsubsection{Model result and uncertainty}

The results presented here were based on equation (7). Both MLE and BA were applied to the seven datasets. Table 3 list the coefficient values, their standard errors, and their lower and upper 95\% prediction coefficient limits obtained from both MLE and BA. In addition, for the BA, the posterior coefficients are reported. T values of coefficients from the MLE were all higher than 2, indicating that there was a good relationship between $\mathrm{Pb}$ concentration and distance from industries in the case study area. A good relationship allows the model to be used to predict $\mathrm{Pb}$ concentrations at other sites.

Table 3 Summary of coefficients obtained from Maximum Likelihood Estimation (MLE) and Bayesian Analysis (BA; posterior coefficients for BA are also shown).

It can be clearly seen that the coefficients from MLE were similar to those from BA (Table 3). However, the SD values for the coefficients obtained from the MLE were larger than for the BA. BA had narrower lower and upper 95\% prediction coefficients.

Fig. 3 Observed lead concentration and estimated uncertainty in lead concentration

Uncertainty directly affected the performance of both methods. Given the limited data in the 
case study, the underlying errors in the dependent variable cannot be ignored. Despite this limitation, simulation of a larger dataset using probability-distributed variables and allowing for uncertainty in the regression model helped establish a more comprehensive model.

Fig. 3 shows the observed $\mathrm{Pb}$ concentration and estimated uncertainty based on the MLE and BA. Both MLE and BA had similar estimates of Pb concentration in the case study area. Notable differences were observed in their uncertainty (95\% prediction limits), with larger uncertainty for MLE. Thus, the BA provided results having slightly smaller uncertainty limits for coefficients than the MLE method. The estimated $\beta$ coefficients from the Monte Carlo simulation are shown in Fig. 4. The oval shape encompassing these estimated $\beta$ coefficients shows that the results of BA were reliable.

Fig. 4 Estimated $\beta$ coefficients from the Monte Carlo simulation

\section{Conclusions}

The $\mathrm{Pb}$ concentrations in the urban dust of JLC ranged from 36.42 to $339.51 \mu \mathrm{g} / \mathrm{g}$, which were all higher than the soil background value of $28.8 \mu \mathrm{g} / \mathrm{g}$ for Jilin Province. Industries had a marked influence on $\mathrm{Pb}$ concentrations in the urban dust, with higher $\mathrm{Pb}$ levels found close to industries in the northern area of JLC. In particular, coal burning and iron ore smelting in the ferroalloy industry contributed heavily to $\mathrm{Pb}$ pollution. The estimated mean $\mathrm{HI}$ value for children was $412 \%$ greater than for adults, confirming that children had a higher exposure risk to $\mathrm{Pb}$ in urban dust, especially in the northern industrial area. A generalized exponential model was developed to estimate the $\mathrm{Pb}$ concentrations in urban dust as a function of distance from multiple industrial sites. The effect of multi-industries was evaluated. Both MLE and BA were applied to 
estimate parameters in our exponential model, relating $\mathrm{Pb}$ concentration in urban dust to distance from multiple industrial sources. Our BA was found to provide better estimates, with narrower confidence intervals.

\section{Acknowledgment}

This research was supported by the Fund for State Key Program of National Natural Science of China (Grant 41530635), Innovative Research Group of the National Natural Science Foundation of China (Grant 51421065), National Science Foundation of China (Grant 51278054),

MYRG072(Y1-L2)-FST13-LIC and China Scholarship Council. The authors are grateful for the support.

\section{Reference}

Acosta, J.A., Faz, A., Kalbitz, K., Jansen, B., Martínez-Martínez, S., 2014. Partitioning of heavy metals over different chemical fraction in street dust of Murcia (Spain) as a basis for risk assessment. J. Geochem. Explor. 144, 298-305.

Acosta, J.A., Gabarrón, M., Faz, A., Martínez-Martínez, S., Zornoza, R., Arocena, J.M., 2015. Influence of population density on the concentration and speciation of metals in the soil and street dust from urban areas. Chemosphere 134, 328-337.

Al-Khashman, O.A., 2004. Heavy metal distribution in dust, street dust and soils from the work place in Karak Industrial Estate, Jordan. Atmos. Environ. 38, 6803-6812.

Apeagyei, E., Bank, M.S., Spengler, J.D., 2011. Distribution of heavy metals in road dust along an urban-rural gradient in Massachusetts. Atmos. Environ. 45, 2310-2323.

Beijing Municipal Research Institute of Environmental Protection (BMRIEP), 2007. Environmental site assessment guideline. Beijing: Beijing Bureau of Quality and Technical Supervision. (in chinese)

Beijing Municipal Research Institute of Environmental Protection (BMRIEP), 2009. Environmental site assessment guideline. Beijing: Beijing Bureau of Quality and Technical Supervision. (in chinese)

Chabukdhara, M., Nema, A.K., 2013. Heavy metals assessment in urban soil around industrial clusters in Ghaziabad, India: Probabilistic health risk approach. Ecotox. Environ. Safe. 87, 57-64.

Chen, H.Y., Li, A.J., Finlow, D.E., 2009. The lead and lead-acid battery industries during 2002 and 2007 in China. J. Power Sources 191, 22-27.

Cheng $\mathrm{H}, \mathrm{Hu}$ Y., 2010. Lead $(\mathrm{Pb})$ isotopic fingerprinting and its applications in lead pollution studies in China: A review. Environ. Pollut. 158, 1134-1146.

China National Environmental Monitoring Center (CNEMC), 1990. The Background 
Concentrations of Soil Elements of China. China Environmental Science Press, Beijing (in Chinese)

De Miguel, E., Iribarren, I., Chacón, E., Ordoñez, A., Charlesworth, S., 2007. Risk-based evaluation of the exposure of children to trace elements in playgrounds in Madrid (Spain). Chemosphere 66, 505-513.

Egodawatta, P., Haddad, K., Rahman, A., Goonetilleke, A., 2014. A Bayesian regression approach to assess uncertainty in pollutant wash-off modelling. Sci. Total Environ. 479-480, 233-240.

Esri. ArcGIS 10.0. https://www.arcgis.com. (accessed 2016.11.09)

Ferreira-Baptista, L., De Miguel, E., 2005. Geochemistry and risk assessment of street dust in Luanda, Angola: A tropical urban environment. Atmos. Environ. 39, 4501-4512.

GB15618, 1995. Soil Environmental Quality Standard (GB15618-1995). (in chinese)

Gelman, A., Carlin, J.B., Stern, H.S., Rubin, D.B., 2014. Bayesian data analysis. Chapman \& Hall/CRC Boca Raton, FL, USA.

Guney, M., Zagury, G.J., Dogan, N., Onay, T.T., 2010. Exposure assessment and risk characterization from trace elements following soil ingestion by children exposed to playgrounds, parks and picnic areas. J. Hazard. Mater. 182, 656-664.

Gunson, A.J., Yue, J., 2001. Artisanal mining in the People's Republic of China. International Institute of Environment and Development, Draft Report.

Haddad, K., Egodawatta, P., Rahman, A., Goonetilleke, A., 2013. Uncertainty analysis of pollutant build-up modelling based on a Bayesian weighted least squares approach. Sci. Total Environ. 449, 410-417.

Huang, M., Wang, W., Chan, C.Y., Cheung, K.C., Man, Y.B., Wang, X., Wong, M.H., 2014. Contamination and risk assessment (based on bioaccessibility via ingestion and inhalation) of metal(loid)s in outdoor and indoor particles from urban centers of Guangzhou, China. Sci. Total Environ. 479-480, 117-124.

Imperato, M., Adamo, P., Naimo, D., Arienzo, M., Stanzione, D., Violante, P., 2003. Spatial distribution of heavy metals in urban soils of Naples city (Italy). Environ. Pollut. 124, 247-256.

Kim, S., Arora, M., Fernandez, C., Landero, J., Caruso, J., Chen, A., 2013. Lead, mercury, and cadmium exposure and attention deficit hyperactivity disorder in children. Environ. Res. 126, 105-110.

Lau, S., Stenstrom, M.K., 2005. Metals and PAHs adsorbed to street particles. Water Res. 39, 4083-4092.

Li, H., Qian, X., Hu, W., Wang, Y., Gao, H., 2013b. Chemical speciation and human health risk of trace metals in urban street dusts from a metropolitan city, Nanjing, SE China. Sci. Total Environ. 456-457, 212-221.

Li, Y., Xiang, L., Tian, P., Liu, J., 2013a. Desorption characteristics of total phosphorus and heavy metals from impervious urban surface sediments. Chinese Sci. Bull. 58, 3357-3360.

Li, Y., Yu, Y., Yang, Z., Shen, Z., Wang, X., Cai, Y., 2016. A comparison of metal distribution in surface dust and soil among super city, town, and rural area. Environ. Sci. Pollut. R. 23, 7849-7860.

Li, Z., Ma, Z., van der Kuijp, T.J., Yuan, Z., Huang, L., 2014. A review of soil heavy metal pollution from mines in China: Pollution and health risk assessment. Sci. Total Environ. 468- 
469, 843-853.

Li, Z., Feng, X., Li, G., Bi, X., Zhu, J., Qin, H., Dai, Z., Liu, J., Li, Q., Sun, G., 2013 c. Distributions, sources and pollution status of 17 trace metal/metalloids in the street dust of a heavily industrialized city of central China. Environ. Pollut. 182, 408-416.

Liu, A., Liu, L., Li, D., Guan, Y., 2015. Characterizing heavy metal build-up on urban road surfaces: Implication for stormwater reuse. Sci. Total Environ. 515-516, 20-29.

Liu, Y., Guo, H., Mao, G., Yang, P., 2008. A Bayesian hierarchical model for urban air quality prediction under uncertainty. Atmos. Environ. 42, 8464-8469.

Lu, X., Wang, L., Lei, K., Huang, J., Zhai, Y., 2009. Contamination assessment of copper, lead, zinc, manganese and nickel in street dust of Baoji, NW China. J. Hazard. Mater. 161, 1058-1062.

Lu X., Wu X., Wang Y., Chen H., Gao P., Fu Y., 2014. Risk assessment of toxic metals in street dust from a medium-sized industrial city of China. Ecotox. Environ. Safe 106, 154-163.

Jilin City Economic and Social Statistical Yearbook editorial board (JLESSY), 2013. Jilin City Economic and Social Statistical Yearbook. Beijing: China Statistics Press. (in chinese)

Madarang, K.J., Kang, J., 2014. Evaluation of accuracy of linear regression models in predicting urban stormwater discharge characteristics. Journal of Environmental Sciences 26, 1313-1320.

Maniquiz-Redillas, M.C., Kim, L.H., 2016. Evaluation of the capability of low-impact development practices for the removal of heavy metal from urban stormwater runoff. Environ. Technol. 37, 2265-2272.

Ministry of Environmental Protection of the People's Republic of China (MEPC), 2013. Exposure Factors Handbook of Chinese population (Adults). Beijing: China Environmental Science Press. (in chinese)

Ordóñez, A., Álvarez, R., De Miguel, E., Charlesworth, S., 2015. Spatial and temporal variations of trace element distribution in soils and street dust of an industrial town in NW Spain: 15years of study. Sci. Total Environ. 524-525, 93-103.

Qing, X., Yutong, Z., Shenggao, L., 2015. Assessment of heavy metal pollution and human health risk in urban soils of steel industrial city (Anshan), Liaoning, Northeast China. Ecotox. Environ. Safe. 120, 377-385.

R Core Team. R statistical software package (version 3.2.4). http://www.r-project.org. (accessed 2016. 11.09)

Shi, G., Chen, Z., Bi, C., Wang, L., Teng, J., Li, Y., Xu, S., 2011. A comparative study of health risk of potentially toxic metals in urban and suburban road dust in the most populated city of China. Atmos. Environ. 45, 764-771.

Song, N., Ma, J., Yu, Y., Yang, Z., Li, Y., 2015. New observations on PAH pollution in old heavy industry cities in northeastern China. Environ. Pollut. 205, 415-423.

Stigliani, W.M., Doelman, P., Salomons, W., Schulin, R., Smidt, G.R., Van der Zee, S.E.A.T., 1991 Chemical time bombs: predicting the unpredictable. Environment: Science and Policy for Sustainable Development 33, 4-30.

US Department of Energy, 2004. RAIS: risk assessment information system. U.S. Department of Energy (DOE), Office of Environmental Management, Oak Ridge Operations (ORO) Office. https://rais.ornl.gov/ Accessed (1119\2016). 
USEPA, 2011. Exposure factors handbook. Washington, D. C.: Environmental Protection Agency, United States.

Wang, J., Ren, H., Zhang, X., 2006. Distribution patterns of lead in urban soil and dust in Shenyang city, Northeast China. Environ. Geochem. Hlth. 28, 53-59.

Wang, Q., Cui, Y., Liu, X., Dong, Y., Christie, P., 2003. Soil contamination and plant uptake of heavy metals at polluted sites in China. Journal of Environmental Science and Health, Part A $38,823-838$

World Health Organization (WHO), 2011. Evaluation of certain food additive and contaminants. World Health Organization technical report series.

Wu, S., Zhou, S., Li, X., 2011. Determining the anthropogenic contribution of heavy metal accumulations around a typical industrial town: Xushe, China. J. Geochem. Explor. 110, 92-97.

Yang, T., Liu, Q., Li, H., Zeng, Q., Chan, L., 2010. Anthropogenic magnetic particles and heavy metals in the road dust: Magnetic identification and its implications. Atmos. Environ. 44, $1175-1185$

Yekeen, T.A., Xu, X., Zhang, Y., Wu, Y., Kim, S., Reponen, T., Dietrich, K.N., Ho, S., Chen, A., Huo, X., 2016. Assessment of health risk of trace metal pollution in surface soil and road dust from e-waste recycling area in China. Environ. Sci. Pollut. R. 23, 17511-17524.

Yu, Y., Li, Y., Li, B., Shen, Z., Stenstrom, M.K., 2016. Metal enrichment and lead isotope analysis for source apportionment in the urban dust and rural surface soil. Environ. Pollut. 216, 764-772.

Zhao, H., Li, X., 2013. Risk assessment of metals in road-deposited sediment along an urban-rural gradient. Environ. Pollut. 174, 297-304.

Zheng, N., Liu, J., Wang, Q., Liang, Z., 2010. Health risk assessment of heavy metal exposure to street dust in the zinc smelting district, Northeast of China. Sci. Total Environ. 408, 726-733.

Žibret, G., Šajn, R., 2008. Modelling of atmospheric dispersion of heavy metals in the Celje area, Slovenia. J. Geochem. Explor. 97, 29-41.

Žibret, G., 2012. Impact of dust filter installation in ironworks and construction on brownfield area on the toxic metal concentration in street and house dust (Celje, Slovenia). Ambio 41, 292-301.

Žibret, G., Van Tonder, D., Žibret, L., 2013. Metal content in street dust as a reflection of atmospheric dust emissions from coal power plants, metal smelters, and traffic. Environ. Sci. Pollut. R. 20, 455-4468. 


\section{List of tables:}

Table 1 Exposure factor definitions and values for the urban dust daily dose model

Table 2 Main sources of $\mathrm{Pb}$ emission from various industries in the north of Jilin

\section{City Center}

Table 3 Summary of coefficients obtained from Maximum Likelihood Estimation (MLE) and Bayesian Analysis (BA; posterior coefficients for BA are also shown).

Table 4 Exposure factor definitions and values for the urban dust daily dose model

\begin{tabular}{|c|c|c|c|c|c|}
\hline & \multirow[b]{2}{*}{ meaning } & \multirow{2}{*}{\multicolumn{2}{|c|}{$\begin{array}{l}\text { chil } \\
\quad d\end{array}$}} & \multirow{2}{*}{$\begin{array}{l}\text { adul } \\
\\
t\end{array}$} & \multirow[b]{2}{*}{ reference } \\
\hline & & & & & \\
\hline & & $\mathrm{mg} /(\mathrm{kg}$. & & & \\
\hline $\mathrm{g}$ & average daily dose of lead through ingestion & d) & - & - & - \\
\hline & & $\mathrm{mg} /(\mathrm{kg}$. & & & \\
\hline $\mathrm{h}$ & average daily dose of lead through inhalation & d) & - & - & - \\
\hline & & $\mathrm{mg} /(\mathrm{kg}$ & & & \\
\hline $\mathrm{rm}$ & average daily dose of lead through dermal contact & d) & - & - & - \\
\hline
\end{tabular}


$\operatorname{IngR}^{\#}$

ingestion rate

EF

ED

exposure duration

average body weight

BW

AT

averaging time for non-carcinogens

InhR

inhalation rate

PEF

particle emission factor

exposed skin area

SA $\mu \mathrm{g} / \mathrm{g}$

$\mathrm{mg} / \mathrm{d}$

100

$\mathrm{d} / \mathrm{a} *$

233

$\mathrm{a}^{*}$

21

42.

$\mathrm{kg}$

7

60.6

$365 \quad 365$

d $\quad \times$ ED

$\times \mathrm{ED}$

$\mathrm{m}^{3} / \mathrm{d}$

5

1.3

$\mathrm{m}^{3} / \mathrm{kg} \quad 2 \times 10^{9}$

$\times 10^{9}$

$160 \quad 435$

$\mathrm{cm}^{2}$

0

$\mathrm{mg} /\left(\mathrm{cm}^{2}\right.$

SL skin adherence factor dermal absorption factor $\cdot d)$

1

1

BMRIEP,2009

$0.0 \quad 0.00$

01

BMRIEP,2009
0

USEPA, 2011; MEPC,

BMRIEP,2007

BMRIEP, 2009; MEPC,

BMRIEP,2009

BMRIEP,2009

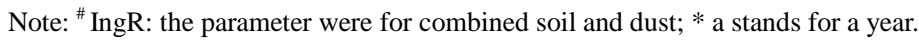

Table 5 Main sources of $\mathrm{Pb}$ emission from various industries in the north of Jilin City Center

\begin{tabular}{llll}
\hline Sit $\quad$ Industry Name & Raw $\quad$ Product & Main \\
\hline
\end{tabular}




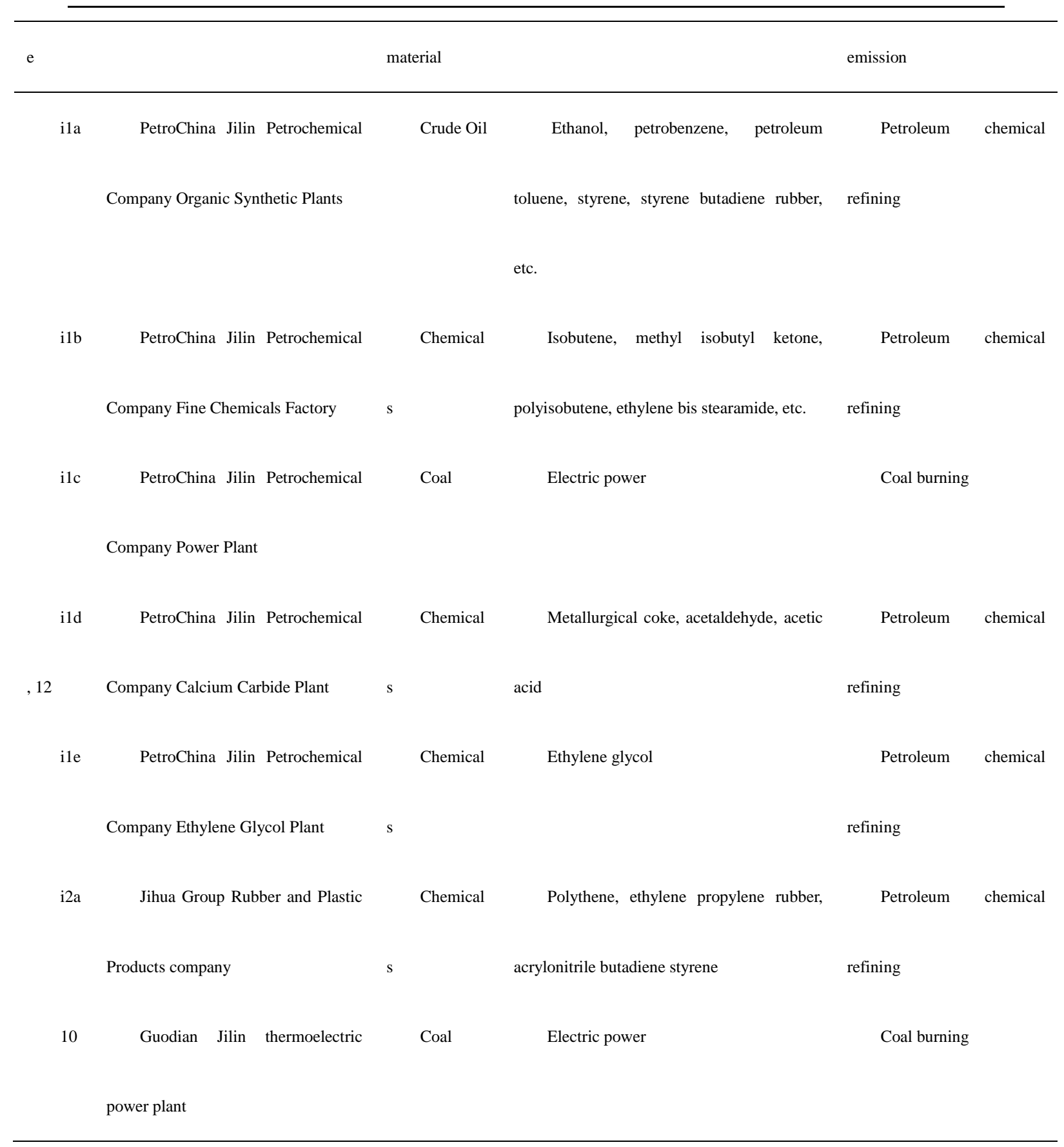

Table 6 Summary of coefficients obtained from Maximum Likelihood Estimation (MLE) and Bayesian Analysis (BA; posterior coefficients for BA are also shown)

\begin{tabular}{|c|c|c|c|c|c|c|c|c|}
\hline Parameter estimation & & SD & & SD & & & & $\beta_{1 \mathrm{U}}$ \\
\hline method & $\beta_{0}$ & of $\beta_{0}$ & $\beta_{1}$ & of $\beta_{1}$ & $\beta_{0 L L}$ & $\beta_{\text {OUL }}$ & $\beta_{1 \mathrm{LL}}$ & $\mathrm{L}$ \\
\hline MLE & 14.4 & 2.54 & -0.1 & 0.09 & 9.49 & 19.4 & -0.3 & -0.0 \\
\hline
\end{tabular}




\begin{tabular}{|c|c|c|c|c|c|c|c|c|}
\hline & 814 & 59 & 842 & 17 & 14 & 714 & 640 & 044 \\
\hline & 14.5 & 1.53 & -0.1 & 0.05 & 11.5 & 17.6 & -0.3 & -0.0 \\
\hline BA & 600 & 93 & 902 & 77 & 599 & 297 & 041 & 750 \\
\hline
\end{tabular}

\section{List of figures:}

Fig. 1 Sampling site and major industry locations in Jilin City Center (JLC), China

Fig. 2 Spatial distribution of health risk assessment through exposure to $\mathrm{Pb}$ in urban dust

Fig. 3 Observed lead concentration and estimated uncertainty in lead concentration

Fig. 4 Estimated $\beta$ coefficients from the Monte Carlo simulation 


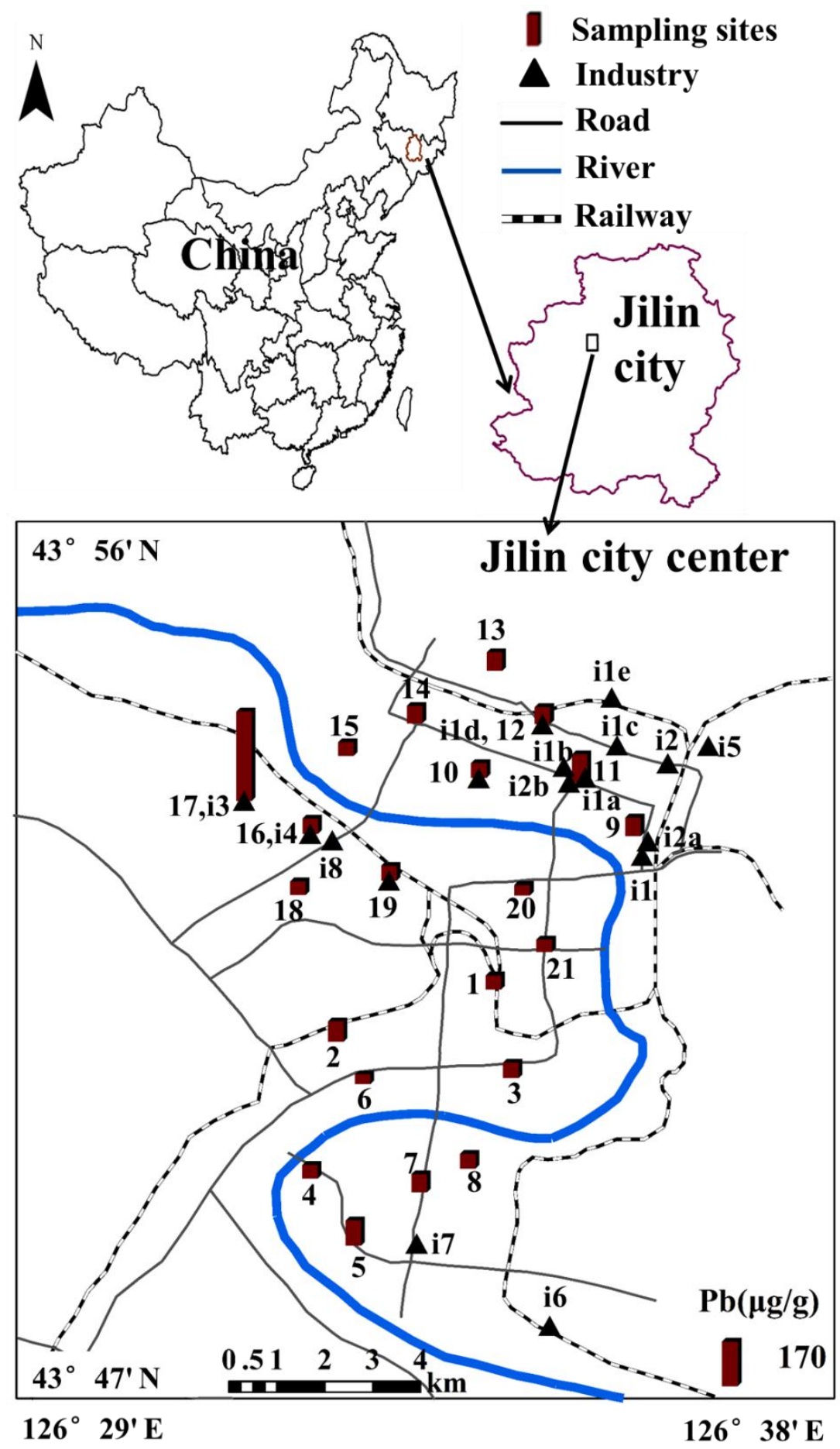

Fig. 1 Sampling site and major industry locations in Jilin City Center (JLC), China. 

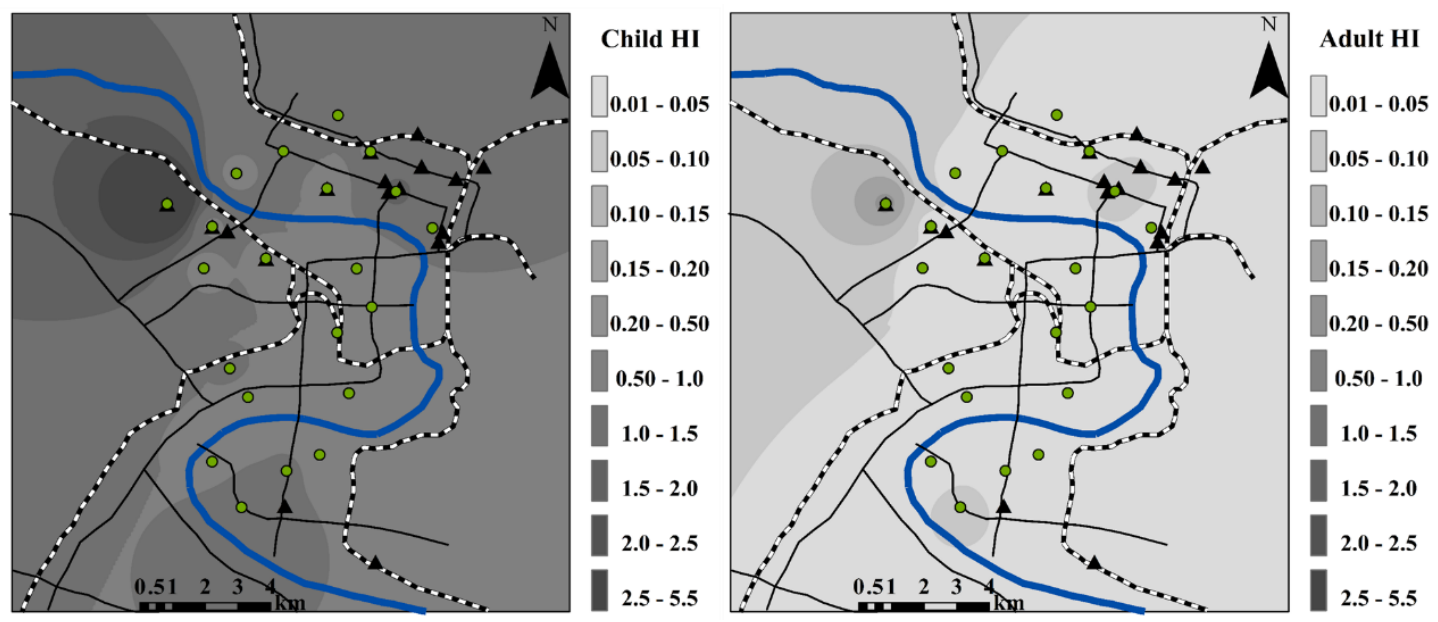

Fig. 2 Spatial distribution of health risk assessment through exposure to $\mathrm{Pb}$ in urban dust 


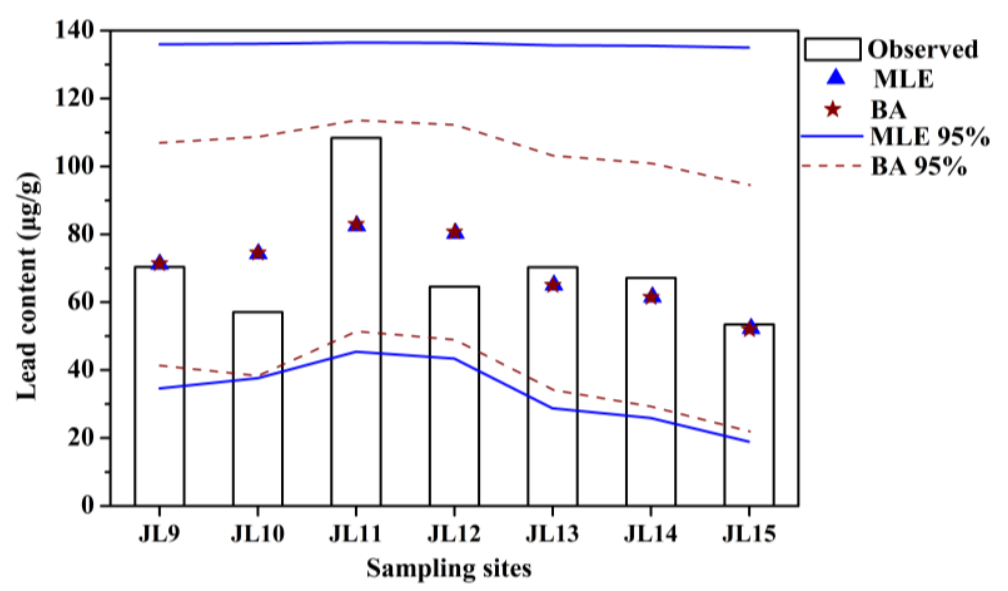

Fig. 3 Observed lead concentration and estimated uncertainty in lead concentration

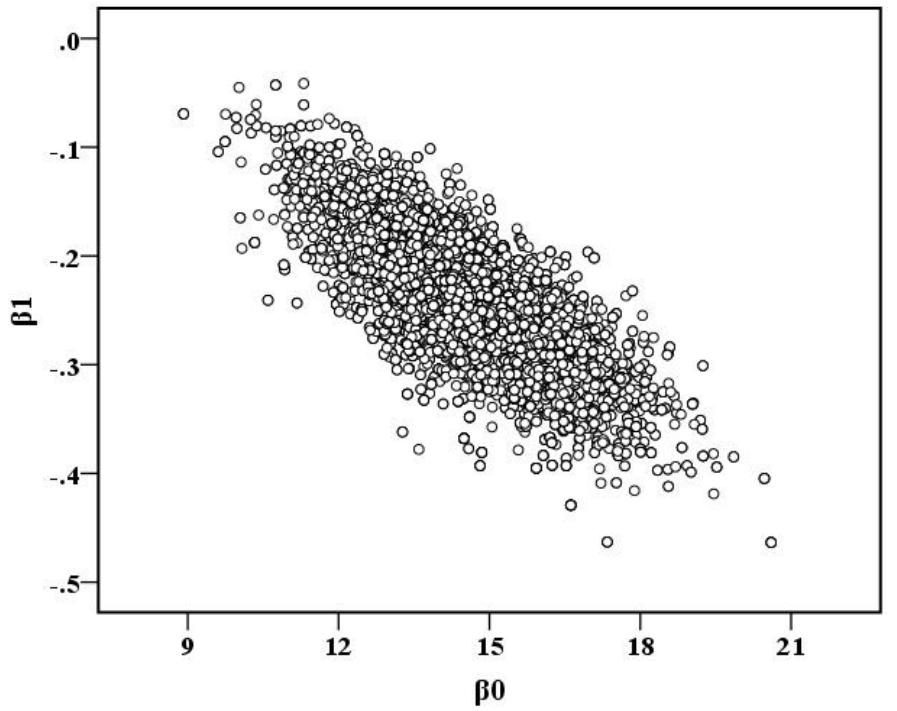

Fig. 4 Estimated $\beta$ coefficients from the Monte Carlo simulation 


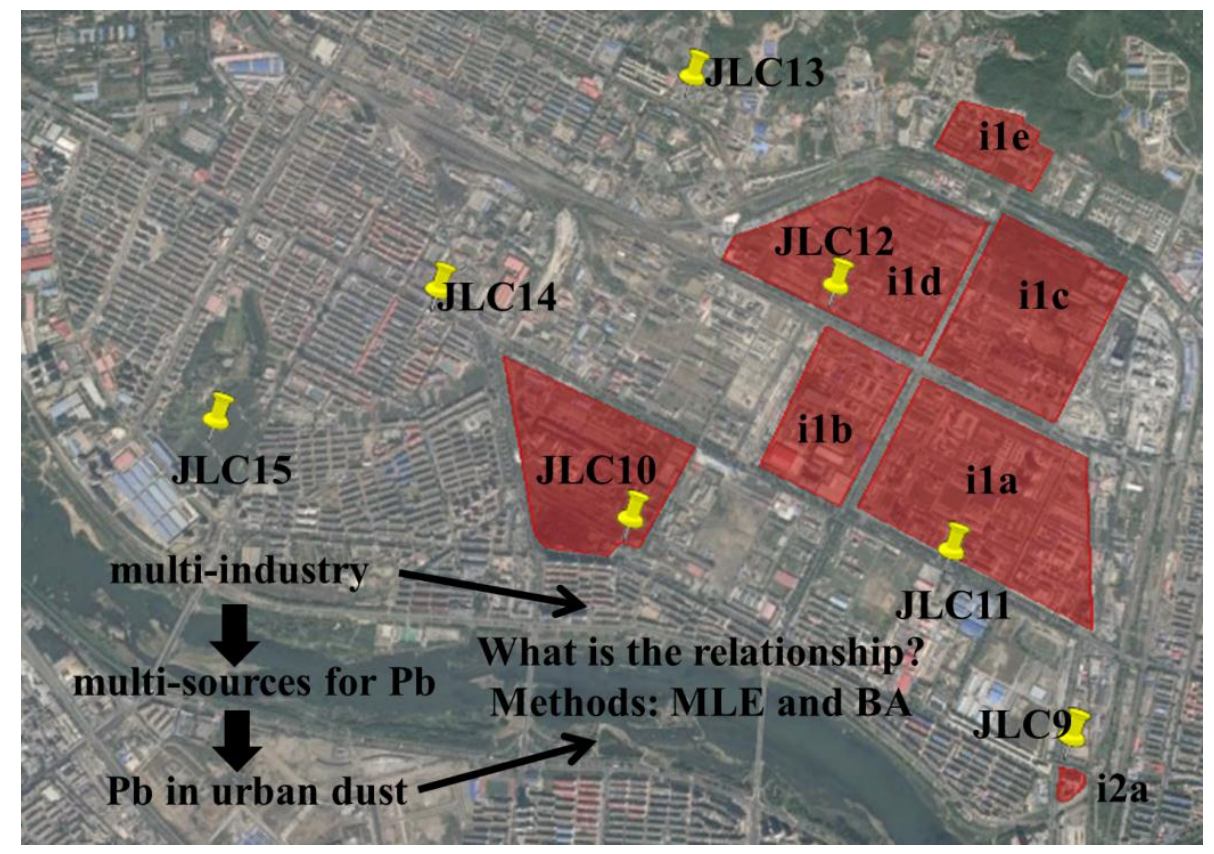

